\title{
Studia Polensia
}

2015, No 4

\section{Editore}

Università Juraj Dobrila di Pola

Dipartimento di studi in lingua italiana

Zagrebačka 30, Pola

\section{Per l'Editore}

Alfio Barbieri, Rettore

\section{Capo redattore}

Elis Deghenghi Olujić

\section{Redazione}

Sergia Adamo (Italia)

Neala Ambrosi-Randić (Croazia)

Danilo Capasso (Bosnia-Erzegovina)

Marina Diković (Croazia)

Fabio Finotti (Italia - USA)

Elvio Guagnini (Italia)

Tanja Habrle (Croazia)

Renate Lunzer (Austria)

Elvi Piršl (Croazia)

Mila Samardžić (Serbia)

Rita Scotti Jurić (Croazia)

\section{Segretaria}

Barbara Ferro Ghiraldo

\section{Recensori}

Sandro Cergna

Marina Diković

Roberta Matković

Elvi Piršl

Marlena Plavšić

Nada Poropat Jeletić

Rita Scotti Jurić

hrcak.srce.hr - Portal znanstvenih časopisa Republike Hrvatske

Lettori

Luigi Casciola (italiano)

Krešimir Vunić (inglese)

Vanessa Vitković Marčeta (croato)

\section{Cover Design}

Tarita Štokovac

\section{Stampa}

Kerschoffset Zagreb d.o.o.

\section{Tiratura}

200

La rivista è pubblicata annualmente. Il primo numero è stato pubblicato nel 2012 . 